\title{
Immediate Effect of Kinesio Taping on Muscle Response in Young Elite Soccer Players
}

\author{
Moisés de Hoyo, Alejandro Álvarez-Mesa, Borja Sañudo, Luis Carrasco, and Sergio \\ Domínguez
}

\begin{abstract}
Context: Kinesio taping (KT) is a new taping technique increasingly used in sports medicine to improve muscle performance; however, its real effect is not entirely known. Objective: To assess the immediate effects of KT on muscle performance in young healthy elite soccer players. Design: Crossover study. Setting: University laboratory. Participants: Eighteen young elite soccer players voluntarily participated in the study (mean \pm SEM: age $18.20 \pm 2.45 \mathrm{y}$, height $1.76 \pm$ $3.56 \mathrm{~m}$, body mass $65.25 \pm 3.76 \mathrm{~kg}$, body-mass index $\left.20.12 \pm 1.25 \mathrm{~kg} / \mathrm{m}^{2}\right)$. Interventions: Each subject completed 2 different protocols, with and without KT. Interventions were performed in a random order, with a washout period between conditions of 1 wk. Main Outcome Measures: Outcome measures included tensiomyographic response in the vastus lateralis and vastus medialis, power output with 30 and $50 \mathrm{~kg}$, countermovement jump, and 10-m sprint. Results: Data showed no significant differences for any of the outcomes analyzed between interventions. Conclusions: KT does not produce a short-term improvement in muscle performance in young elite soccer players.
\end{abstract}

Keywords: tensiomyography, muscle performance, leg-extension muscles

It has been demonstrated that elite soccer players not only require sport-specific technical and tactical skills, but explosive strength and speed are also essential for optimal performance. ${ }^{1,2}$ Consequently, in recent years there has been a heightened focus on designing and implementing training methods and techniques to improve these aspects of athletic performance. In the field of sports medicine, the application of different types of tape has been used for many years to prevent injury, but more recently taping techniques are being used to increase muscle performance. The proposed physiological basis of traditional tape and taping techniques was that taping the skin would stimulate cutaneous mechanoreceptors and therefore enhance the delivery of sensory input from the periphery to the central nervous system. This increased sensory input would then result in greater information integration and a significant improvement in proprioception and muscle performance. ${ }^{3-8}$ However, it should be taken into account that joint movement might be limited. ${ }^{9,10}$

In recent years, the use of a new form of cotton tape with acrylic adhesive, known as kinesio tape (KT), has proliferated. This tape differs from traditional tape due to it is elasticity-it can be stretched to up to $120 \%$ to $140 \%$ of its original length before being applied to the skin. ${ }^{11}$ Another difference from traditional tape is that KT can provide a pulling force to the skin and supposedly

de Hoyo, Sañudo, and Carrasco are with the Dept of Physical Education and Sport, University of Seville, Spain. Álvarez-Mesa and Domínguez are with Medical Services of Seville Soccer Club, Seville, Spain. increase the distance between the fascia and the soft tissue under the areas where it is applied. ${ }^{12}$ In addition, KT does not restrict joint movement in the same way that traditional taping does and can be worn for longer periods of time without the need for reapplication. ${ }^{13,14}$

It is also argued that KT can be used not only to increase muscle performance ${ }^{15}$ but also to normalize muscle function, to increase lymphatic and vascular flow, to diminish pain, and to aid in the correction of possible articular malalignments. ${ }^{13,16}$ While KT techniques are frequently applied to patients with musculoskeletal system disorders, especially in the field of sports injuries, ${ }^{17}$ most of the supposed effects are hypothesized, and there is no evidence in the literature supporting the effects of KT taping.

The real effects of KT on muscle performance are still being investigated; several authors have hypothesized that the KT facilitates immediate increases in muscle strength by producing a concentric pull on the fascia, which may then stimulate increased muscle contraction, ${ }^{18}$ or that KT improves muscle alignment, which may contribute to marginal increases in muscle strength. ${ }^{19}$ Slupik et $\mathrm{al}^{20}$ demonstrated an increase in peak torque (24 h) and electromyographic activity $(72 \mathrm{~h})$ in the vastus medialis of healthy individuals after application of KT tape. Huang et $\mathrm{al}^{21}$ investigated the effect of elastic taping on the triceps surae during a maximal vertical jump. They observed that vertical ground-reaction force and electromyographic activity of the gastrocnemius medialis increased when KT was applied, although the height of jump remained constant. Hsu et $\mathrm{al}^{19}$ observed an incremental increase in lower trapezius muscle strength after a taping application. Lee et $\mathrm{al}^{22}$ showed greater grip 
strength after applying KT to the flexor muscles than that of the untaped muscles. In contrast, $\mathrm{Fu}$ et $\mathrm{al}^{23}$ demonstrated that concentric and eccentric muscle strength of the quadriceps and hamstrings were not affected by KT in healthy people. Similarly, Chang et al ${ }^{11}$ evaluated the effects of KT on maximal grip strength of the dominant hand in healthy college athletes and did not find any significant effect.

It seems that KT in soccer players is being used without knowing its real effects on muscle performance. The aim of this study was therefore to determine the immediate effects of KT on strength, jump ability, speed, and muscle contractile properties in young elite soccer players.

\section{Materials and Methods}

\section{Participants}

Eighteen elite soccer players voluntarily participated for the study (mean \pm SEM: age $18.20 \pm 2.45 \mathrm{y}$, height $1.76 \pm$ $3.56 \mathrm{~m}$, body mass $65.25 \pm 3.76 \mathrm{~kg}$, body-mass index $\left.20.12 \pm 1.25 \mathrm{~kg} / \mathrm{m}^{2}\right)$. All subjects had a similar training volume (minimum $4 \mathrm{~d} / \mathrm{wk}$ and maximum $5 \mathrm{~d} / \mathrm{wk}$ ), which included 2-hour sessions per day. Each subject was randomly assigned to 1 of 2 different experimental conditions, 1 with KT (KTi) and 1 without KT (NKTi). The rest period between experimental conditions was 1 week to avoid carryover effects from previous sessions. All sessions were conducted under the same conditions ( $24 \mathrm{~h}$ without physical activity and at the same hour of the day). Each participant was informed about the study procedure with its possible benefits and risks, and each gave signed written consent. The study was approved by the local ethics committee.

\section{Procedures}

Each testing session consisted on the following actions: application (or not) of KT on the rectus femoris of the dominant leg, assessment of muscle contractile properties of the vastus lateralis and vastus medialis using tensiomyographic response (TMG), standardized warmup, and performance tests.

\section{KT Technique.}

Standard 2-in (5-cm) black KT (Cure Tape, FysioTape BV, Enschede, The Netherlands) was used. The tape was applied by an experienced physiotherapist following the Y-shaped KT technique proposed by Kase et $\mathrm{al}^{13}$ and $\mathrm{Fu}$ et $\mathrm{al}^{23}$ for the rectus femoris. Participants lay in supine position with the hip flexed $30^{\circ}$ and the knee flexed $60^{\circ}$. The tape was applied from a point $10 \mathrm{~cm}$ below the anterosuperior iliac spine, bisected at the junction between the quadriceps tendon and the patella, and circled around the patella, ending at its inferior side. The first $5 \mathrm{~cm}$ of tape were not stretched and acted as the anchor. The portion between the anchor and superior patella was stretched to $120 \%$ using a reference scale. The remaining tape around the patella remained unstretched. Figure 1 shows the KT technique used.
$1<<<<<<<<<$ FIGURE 1 - $>>>>>>>>>>1$

TMG.

The TMG technique is based on measuring skeletalmuscle contractile response to a low-level electrical stimulus. ${ }^{24}$ This technique produces radial displacement of the muscle belly in response to an electrical stimulus conducted through the underlying muscle tissue. ${ }^{25}$ The radial displacement of the muscle belly can be measured with a displacement sensor (TMG System 100, TMGBMC Ltd, Slovenia). Displacement-time-curve recordings allow muscle contractile properties to be assessed, obtaining different parameters that can inform about muscle tone. ${ }^{24}$

Maximal radial displacement $(\mathrm{Dm})$, time from the onset of electrical stimulus to $10 \%$ of Dm, time from $10 \%$ to $90 \%$ of $\mathrm{Dm}$ in the ascending curve (Tc), time between $50 \%$ of Dm on both sides of the curve (Ts), and time from $90 \%$ to $50 \%$ of $\mathrm{Dm}$ on the descending curve $(\mathrm{Tr})$ were determined. Reliability of TMG has been established according Tous-Fajardo et al. ${ }^{24}$

During each protocol, TMG analysis of the vastus lateralis and vastus medialis was performed. Radial displacements were measured under static and relaxed conditions, with the participant in the supine position and the knee joint fixed at an angle of $120^{\circ}\left(180^{\circ}\right.$ corresponding to full extension of the knee). The measured limb was positioned on a triangular wedge foam cushion to keep a fixed knee angle. A digital displacement transducer (GK 40, Panoptik d.o.o., Ljubljana, Slovenia) that incorporates a spring of $0.17 \mathrm{~N} / \mathrm{mm}$ was set perpendicular to the muscle belly to acquire radial displacement. Sensor location was determined anatomically according to Delagi et $\mathrm{al}^{26}$ and marked with a dermatological pen. Two square $(5 \times 5 \mathrm{~cm}) 2$-mm-thick self-adhesive electrodes (Compex Medical SA, Ecublens, Switzerland) were placed symmetrically $5 \mathrm{~cm}( \pm 3 \mathrm{~cm})$ to the sensor tip. A TMG-S1 (EMF-Furlan and Co, d.o.o., Ljubljana, Slovenia) stimulator was used.

Regarding electrical stimulation procedures, pulse duration was 1 millisecond and the amplitude was set at $100 \mathrm{~mA}$. None of the participants reported discomfort during electrical stimulation.

\section{Warm-Up.}

After TMG analysis, all subjects performed a 5-minute warm-up $(3 \mathrm{~min}$ at $60 \mathrm{~W}+2 \mathrm{~min}$ at $80 \mathrm{~W})$ at $60 \mathrm{rpm}$ on a cycle ergometer (C3 Advanced, Life Fitness, EEUU) followed by 10 repetitions with $20 \mathrm{~kg}$ in a half-squat exercise. After a standardized warm-up, power output, countermovement jump, and speed at $10 \mathrm{~m}$ were assessed in this order, with a rest period between tests of 3 minutes.

\section{Power Output.}

Participants adopted a half-squat position with shoulders touching the bar, and the starting knee angle for movement execution was set at $90^{\circ}$. From this position, participants performed a concentric activation of the legextensor muscles until reaching full extension at $180^{\circ}$. They were given instructions to perform a purely 
concentric action from the starting point, keeping shoulders at an abducted position of $90^{\circ}$ to ensure consistency of shoulder and elbow joints during the movement execution. ${ }^{27}$ Such movement was performed on a Multipower (Smith Machine, Life Fitness, EEUU) using 2 different loads (both 30 and $50 \mathrm{~kg}$ are the most common loads used in daily training) to estimate maximal power output. A linear encoder (T-Force, T-Force System, Ergotech, Spain) was used, which has a microprocessor that works internally with a $10-\mu$ s resolution. The optical transducer signal interrupts the microprocessor at each 0.07-mm displacement, which lets us perform kinematic analysis. The rest period between repetitions was 90 seconds.

\section{Countermovement Jump.}

Lower body explosive-strength characteristics, expressed as elevation of the body's center of gravity (vertical jump), were assessed using an infrared-ray platform built into the Opto Jump System (Opto Jump, Microgate, Italy) according to Cronin and McLean. ${ }^{28}$ The test starts with a preparatory movement of knee extension going down to $90^{\circ}$ knee flexion and, without pausing, jumping upward as high as possible. The jump was performed without the use of the arms; participants were asked to keep their hands on their hips. Elevation of the center of gravity (height in meters) above ground level was calculated for both tests, as was flight time $\left(t_{v}\right)$ in seconds, applying the laws of ballistics:

$$
H=t_{v}^{2} \times g / 8
$$

where $H$ is the height $(\mathrm{m})$ and $g$ is the gravitational acceleration $\left(9.81 \mathrm{~m} / \mathrm{s}^{2}\right)$. Participants performed 2 jumps separated by 90 seconds. The mean score was used for statistical analysis.

\section{0-m-Sprint Test.}

Participants' running speed was evaluated with a $10-\mathrm{m}$ sprint effort using dual-beam electronic timing gates (Ergo Timer, Globus, Italy) and methods previously described. ${ }^{29}$ Participants were instructed to run as quickly as possible along the $10-\mathrm{m}$ distance from a standing start. They started from a stationary, upright position with the front foot on the 1-m point in front of the line with the start gate. Speed was measured to the nearest 0.01 second, with the mean score from 2 trials used as the speed score. Two minutes of rest between the 2 trials was given.

\section{Reproducibility of Variables}

Tests were repeated on 3 different days (Monday, Wednesday, and Friday) in the week before training. The intraclass correlation values (interday) were power $=.94$, countermovement jump $=.95$, and sprint test $=.92$.

\section{Statistical Analyses}

Means and standard errors of the mean (SEM) were calculated for each variable. Normality was checked using the Kolmogorov-Smirnov test, and all variables were normally distributed. One-way analysis of variance
(ANOVA) was performed to check differences between interventions (KTi and NKTi). Statistical significance was set at $P<.05$.

\section{Results}

In relation to physical-performance tests, the application of KT lead to $0.45 \% \pm 1.43 \%$ and $0.74 \% \pm 2.29 \%$ increases for power output with $30 \mathrm{~kg}$ and $50 \mathrm{~kg}$, respectively; an increase of $1.97 \% \pm 1.57 \%$ for the countermovement-jump test; and an increase of $0.10 \% \pm$ $0.66 \%$ for the $10-\mathrm{m}$-sprint test. However, these differences did not reach statistical significance, as shown in Figure 2. $1<<<<<<<<<$ FIGURE $2>>>>>>>>>>>1$

Regarding the TMG measurements, Table 1 shows results for all outcomes in both the KTi and the NKTi protocol. The ANOVA test for interprotocol comparison showed no significant differences for the vastus lateralis and vastus medialis in any of the variables considered. $1<<<<<<<<<$ TABLE 1 1 $>>>>>>>>>>>1$

\section{Discussion}

The aim of this study was to determine the short-term efficacy of KT on muscle performance in young elite soccer players. Our results demonstrate that muscle response, jump ability, $10-\mathrm{m}$ sprint, and power output do not significantly change after the application of KT. These findings may be important, as many athletes, both amateurs and professionals, are using this kind of tape based on the premise that it will improve their performance.

Regarding the muscle response, to our knowledge no studies have analyzed the TMG response after different tape treatments. In the field of sport rehabilitation few studies have analyzed TMG parameters to provide useful information about muscle activation. ${ }^{30}$ However, our study has shown that Dm (which could be equated to electrically evoked peak twitch torque) is representative of muscle tone and contractile force. ${ }^{25,31}$ Contraction-time parameters such as Ts and $\operatorname{Tr}$ show the largest influence on muscle activation and fatigue rate, ${ }^{30}$ or Tc, which is related to muscle-composition parameters such as fibertype distribution ${ }^{32-34}$ and speed of force generation. ${ }^{34}$ In the current study, TMG analysis of the vastus lateralis and vastus medialis of the dominant leg showed no statistically significant differences between the two interventions in Dm, Tc, Ts, and Tr. These results indicate that there was no effect of KT on muscle contractile properties.

These results contrast with those reported by Slupik et $\mathrm{al}^{20}{ }^{20}$ who showed an increase in muscle tone when KT was applied to support the muscle and suggested that it may be due to a reflex effect on the nervous system. This effect may be due to an increase in the number of motor units recruited during maximal contraction, an increase in muscle tone generated by individual units, or the joint effect of both mechanisms. Morrissey ${ }^{35}$ and Sijmonsma, ${ }^{14}$ argue that when the tape is applied in the direction of 
muscle fibers the muscle tone might increase, and therefore it may facilitate the strength of the underlying muscle. However, in the current study all TMG parameters showed no significant effects when the KT was applied; it is therefore apparent that there is no clear relationship between increased muscle tone and KT.

When short-term effects of KT on muscle performance were analyzed, our results agree with those of $\mathrm{Fu}$ et $\mathrm{al}^{23}$ and Slupik et al, ${ }^{20}$ who did not find positive effects of KT on peak torque during isokinetic activations of the leg muscles immediately and after 10 minutes of taping, respectively. Hsu et $\mathrm{al}^{19}$ investigated the effect of elastic taping on strength of the scapular muscles in baseball players with shoulder impingement. Compared with the placebo taping, the strength of the lower trapezius had a tendency to increase after KT application, but again this response was not statistically significant. However, Huang et $\mathrm{al}^{21}$ showed increases in electromyographic activity and reaction force when KT was applied on the calf muscle, but jump height did not improve.

When they assessed the long-term effect of KT, Fu et $\mathrm{al}^{23}$ found no significant increase in muscle strength 12 $\mathrm{h}$ after application of the tape. However, Slupik et $\mathrm{al}^{20}$ showed that KT has a positive effect on muscle activity 24 and 72 hours (but not $96 \mathrm{~h}$ ) after taping. Long-term effects were not analyzed in the current study, but it may be that KT's effects are more apparent 24 to 72 hours after its placement.

Several theories have tried to explain these contradictory results. Slupik et $\mathrm{al}^{20}$ suggested that effects of KT may be due to an increased recruitment of the muscle's motor units. However, Ridding et $\mathrm{al}^{37}$ and Simoneau et $\mathrm{al}^{38}$ hypothesize that tactile input has been reported to interact with motor control by altering the excitability of the central neuron system. Huang et $\mathrm{al}^{21}$ indicate that the muscle that contributes the most during an activity may reflect larger electromyographic change with KT. In addition, Alexander et $\mathrm{al}^{39}$ reported that the longitudinal strip may shorten the muscle fibers, producing a decrease in the afferent Ia discharge from the neuromuscular spindle, causing a reduction in the motor neurons of the medullar anterior horn, proved by the diminished amplitude of the $\mathrm{H}$ reflex observed. According to Hsu et al, ${ }^{19}$ the reason $\mathrm{KT}$ application could lead to the immediate marginal increase in muscle strength can be explained by the results of the facilitated muscle activity and improved joint alignment.

The negative results observed in the current study may be explained by the fact that afferent stimuli generated by KT may not be strong enough to modulate muscle performance of healthy soccer players. Another possible explanation for these results may be type of tape, as was suggested by Hsieh et al. ${ }^{40}$ In addition, unlike most studies in the field, in this investigation functional muscleperformance tests were used, which may be less sensitive to change (but more clinical and functionally relevant), which could explain the differences found between our results and those of others. In addition, the functional tests used higher loads, facilitating greater muscle-fiber recruitment and motor-unit synchronization, but these loads are less used in daily soccer-training routines.

Finally, our study had some limitations that should be considered. Tape localization and/or trajectories on the target limb, joint, or muscle and application technique used by the therapist can influence the effect of KT on muscle performance. In our study, a standard 2-in $(5-\mathrm{cm})$ black KT was used, and an experienced physiotherapist applied it in all cases following the Y-shaped KT technique proposed by Kase et $\mathrm{al}^{13}$ and $\mathrm{Fu}$ et $\mathrm{al}^{23}$ However, subtle differences in tape and application used across the studies may account for some of the differences.

\section{Conclusions}

In conclusion, there is no short-term effect of KT on contractile properties and muscle performance in young elite soccer players. However, new studies are needed to confirm long-term effects of KT 24 to 72 hours after taping.

\section{References}

1. Rampinini E, Bishop D, Marcora SM, Ferrari-Bravo D, Sassi R, Impellizzeri FM. Validity of simple field tests as indicators of match-related physical performance in top-level professional soccer players. Int $J$ Sports Med. 2007;28:228-235. PubMed doi:10.1055/s-2006-924340

2. Impellizzeri FM, Rampinini E, Castagna $\mathrm{C}$, et al. Validity of a repeated-sprint test for football. Int $J$ Sports Med. 2008;29:899-905. $\quad$ PubMed doi:10.1055/s-2008-1038491

3. Callaghan MJ, Selfe J, Bagley PJ, Oldham JA. The effects of patellar taping on knee joint proprioception. J Athl Train. 2002;37:19-24. PubMed

4. Callaghan MJ, Selfe J, McHenry A, Oldham JA. Effects of patellar taping on knee joint proprioception in patients with patellofemoral pain syndrome. Man Ther. 2008;13:192-199. doi:10.1016/i.math.2006.11.004

5. Hughes T, Rochester P. The effects of proprioceptive exercise and taping on proprioception in subjects with functional ankle instability: a review of the literature. Phys Ther Sport. 2008;9:136-147. PubMed doi:10.1016/j.ptsp.2008.06.003

6. Refshauge KM, Raymond J, Kilbreath SL, Pengel L, Heijnen I. The effect of ankle taping on detection of inversion-eversion movements in participants with recurrent ankle sprain. Am $J$ Sports Med. 2009;37:371-375. doi: $10.1177 / 0363546508324309$

7. McConnell J. The physical therapist's approach to patellofemoral disorders. Clin Sports Med. 2002;21:363-387. PubMed doi:10.1016/S02785919(02)00027-3

8. McConnell J. Rehabilitation and nonoperative treatment of patellar instability. Sports Med Arthrosc. 
$2007 \cdot 15 \cdot 95-104$ doi:10.1097/JSA.0b013e318054e35c

$\underline{\text { PubMed }}$

9. Bennell KL, Goldie PA. The differential effects of external ankle support on postural control. J Orthop Sports Phys Ther. 1994;20:287-295. PubMed

10. MacKean LC, Bell G, Burnham RS. Prophylactic ankle bracing vs taping: effects on functional performance in female basketball players. J Orthop Sports Phys Ther. 1995;22:77-81. PubMed

11. Chang HY, Chou KY, Lin JJ, Lin CF, Wang CH. Immediate effect of forearm kinesio taping on maximal grip strength and force sense in healthy collegiate athletes. Phys Ther Sport. 2010;11:122127. PubMed doi:10.1016/i.ptsp.2010.06.007

12. Kase K, Wallis J, Kase T. Clinical Therapeutic Applications of the Kinesio Taping Method. Tokyo, Japan: Ken Ikai Co. Ltd; 2003.

13. Kase K, Tatsuyuki H, Tomoko O. Development of Kinesio Tape. Kinesio Taping Perfect Manual. Tokyo, Japan: Kinesio Taping Association; 1996.

14. Sijmonsma J. Manual de Taping Neuro Muscular. Portugal[AUQ1]: Aneid Press; 2007.

15. Firth BL, Dingley P, Davies ER, Lewis JS, Alexander CM. The effect of kinesiotape on function, pain, and motoneuronal excitability in healthy people and people with Achilles tendinopathy. Clin J Sport Med. 2010;20:416-421. doi:10.1097/JSM.0b013e3181f479b0

PubMed

16. Williams S, Whatman C, Hume PA, Sheerin K. Kinesio taping in treatment and prevention of sports injuries: a meta-analysis of the evidence for its effectiveness. Sports Med. 2012;42:153-164. PubMed doi:10.2165/11594960-000000000-00000

17. Yasukawa A, Patel P, Sisung C. Pilot study: investigating the effects of kinesio taping in an acute paediatric rehabilitation setting. Am J Occup Ther. 2006;60:104-110. PubMed doi:10.5014/ajot.60.1.104

18. Hammer WI. Functional Soft-Tissue Examination and Treatment by Manual Methods. 3rd ed. Boston, MA: Jones \& Bartlett; 2006.

19. Hsu YH, Chen WY, Lin HC, Wang WT, Shih YF. The effects of taping on scapular kinematics and muscle performance in baseball players with shoulder impingement syndrome. $J$ Electromyogr Kinesiol. 2009;19:1092-1099. doi:10.1016/i.jelekin.2008.11.003

PubMed

20. Slupik A, Dwornik M, Bialoszewski D, Zych E. Effect of kinesio taping on bioelectrical activity of vastus medialis muscle: preliminary report [article in English, Polish]. Ortop Traumatol Rehabil. 2007;9(6):644-651. PubMed

21. Huang CY, Hsieh TH, Lu SC, Su FC. Effect of the kinesio tape to muscle activity and vertical jump performance in healthy inactive people. Biomed Eng Online. 2011;10:70. PubMed doi:10.1186/1475$925 \mathrm{X}-10-70$

22. Lee JH, Yoo WG, Lee KS. Effects of head-neck rotation and kinesio taping of the flexor muscles on dominanthand grip strength. J Phys Ther Sci. 2010;22:285289. doi: $10.1589 /$ ipts. 22.285
23. Fu TC, Wong A, Pei YC, Wu KP, Chou SW, Lin YC. Effect of kinesio taping on muscle strength in athletes-a pilot study. $J$ Sci Med Sport. 2008;11:198-201. doi:10.1016/i.jsams.2007.02.011

24. Tous-Fajardo J, Moras G, Rodríguez-Jiménez S, Usach R, Moreno D, Maffiuletti NA. Inter-rater reliability of muscle contractile property measurements using noninvasive tensiomyography. J Electromyogr Kinesiol. 2010;20:761-766 doi:10.1016/j.jelekin.2010.02.008

25. Hunter AM, Galloway SD, Smith IJ, et al. Assessment of eccentric exercise-induced muscle damage of the elbow flexors by tensiomyography. J Electromyogr Kinesiol. 2012;22(3):334-341. PubMed doi:10.1016/j.jelekin.2012.01.009

26. Delagi EF, Perotto A, Iazzetti J, Morrison D. Anatomic Guide for the Electromyographer. Springfield, IL: Charles C. Thomas; 1975.

27. Newton RU, Murphy AJ, Humphries BJ, Wilson GJ, Kraemer WJ, Häkkinen K. Influence of load and stretching shortening cycle on the kinematics, kinetics and muscle activation that occurs during explosive upper-body movements. Eur J Appl Physiol. 1997;75:333-342. doi:10.1007/s004210050169

28. Cronin J, McLean A. Functional measurement of leg extension musculature: protocols, research and clinical applications. N Z J Sports Med. 2000;27:4043.

29. Baker D, Nance S. The relationship between running speed and measures of strength and power in professional Rugby League players. J Strength Cond Res. 1999;13:230-235.

30. Krizaj D, Simunic B, Zagar T. Short-term repeatability of parameters extracted from radial displacement of muscle belly. J Electromyogr Kinesiol. 2008;18:645651. PubMed doi:10.1016/i.jelekin.2007.01.008

31. Pisot R, Narici MV, Simunic B, et al. Whole muscle contractile parameters and thickness loss during 35 day bed rest. Eur J Appl Physiol. 2008;104:409-414. PubMed doi:10.1007/s00421-008-0698-6

32. Dahmane R, Valen i V, Knez N, Er en I. Evaluation of the ability to make non-invasive estimation of muscle contractile properties on the basis of the muscle belly response. Med Biol Eng Comput. 2001;39:51-55. PubMed doi:10.1007/BF02345266

33. Dahmane R, Djordjevic S, Simunic B, Valencic V. Spatial fiber type distribution in normal human muscle: histochemical and tensiomyographical evaluation. J Biomech. 2005;38:2451-2459. PubMed doi:10.1016/i.jbiomech.2004.10.020

34. Simunic B, Degens H, Rittweger J, Narici M, Mekjavic IB, Pisot R. Noninvasive estimation of myosin heavy chain composition in human skeletal muscle. $\mathrm{Med} \mathrm{Scl}$ Sports Exerc. 2011;43:1619-1625. $\quad$ PubMed doi:10.1249/MSS.0b013e31821522d0

35. Morrissey D. Proprioceptive shoulder taping. J Bodyw Mov Ther. 2000;4:189-194. doi:10.1054/jbmt.2000.0156

36. Vithoulk I, Bencka A, Malliou P, Aggelousisb N, Karatsolisa K, Diamantopoulos K. The effects of kinesio taping on quadriceps strength during 
isokinetic exercise in healthy non-athlete women. Isokinet Exerc Sport. 2010;18:1-6. [AUQ2]

37. Ridding MC, Brouwer B, Miles TS, Pitcher JB, Thompson PD. Changes in muscle responses to stimulation of the motor cortex induced by peripheral nerve stimulation in human subjects. Exp Brain Res. 2000;131:135-143.

PubMed doi:10.1007/s002219900269

38. Simoneau GG, Degner RM, Kramper C, Kittleson KH. Changes in ankle joint proprioception resulting from strips of athletic tape applied over the skin. J Athl Train. 1997;32:141-147. PubMed

39. Alexander CM, McMullan M, Harrison PJ. What is the effect of taping along or across a muscle on motoneurone excitability?: a study using triceps surae. Man Ther. 2008;13:57-62. PubMed doi:10.1016/j.math.2006.08.003

40. Hsieh TS, Wu PL, Liao JH, et al. Does elastic taping on the triceps surae facilitate the ability of vertical jump? Orthopaedics. 2007;13:30.

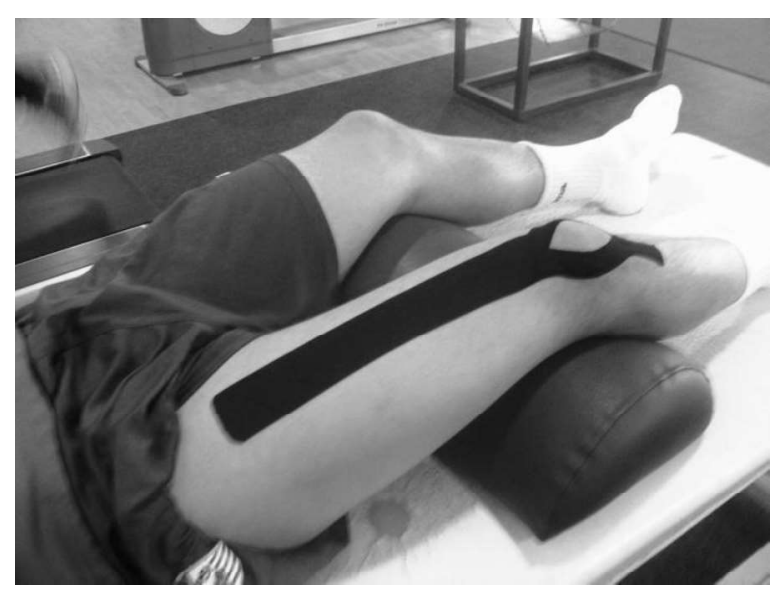

Figure 1 - The taping method and subject posture employed when applying Kinesio taping.
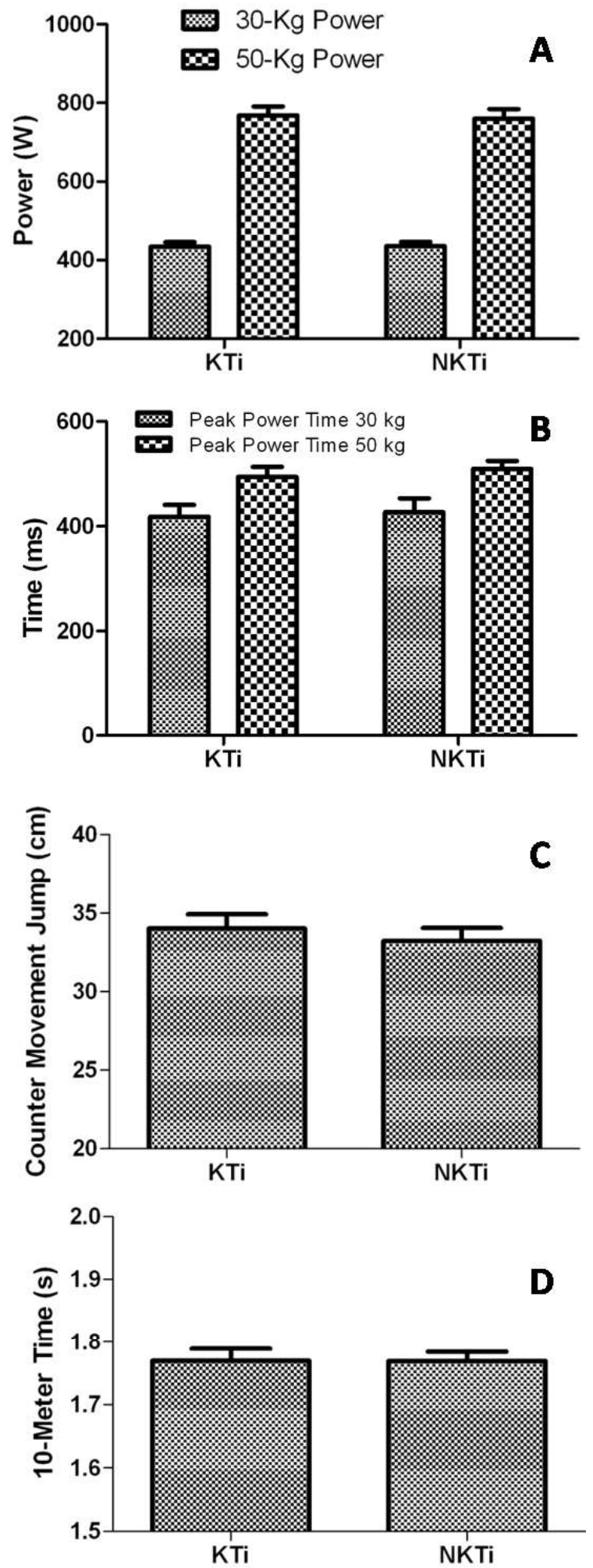

Figure 2 - Interprotocol comparison for (A) power output, (B) peak power time, (C) countermovement jump, and (D) 10-m time. Abbreviations: KTi, kinesio taping; NKTi, no kinesio taping. 
de Hoyo et al

Table 1 Tensiomyographic Measurements in Both Interventions

\begin{tabular}{llcccc}
\hline & & \multicolumn{3}{c}{ Group } \\
\cline { 3 - 5 } Muscle & Measure & Kinesio taping, mean \pm SEM & No kinesio taping, mean \pm SEM & $F$ & $P$ \\
\hline Vastus medialis & contraction time (ms) & $24.48 \pm 0.67$ & $24.88 \pm 0.75$ & 0.560 & .931 \\
& substation time (ms) & $185.38 \pm 9.99$ & $181.53 \pm 11.09$ & 0.498 & .959 \\
& relaxation time (ms) & $79.46 \pm 10.83$ & $70.55 \pm 13.58$ & 0.210 & .866 \\
& maximum distance (mm) & $5.20 \pm 0.28$ & $5.82 \pm 0.38$ & 0.928 & .391 \\
& delayed time (ms) & $19.19 \pm 0.40$ & $20.07 \pm 0.46$ & 1.373 & .277 \\
Vastus lateralis & contraction time (ms) & $20.81 \pm 0.45$ & $20.87 \pm 0.98$ & 0.169 & .845 \\
& substation time (ms) & $78.24 \pm 9.91$ & $81.93 \pm 11.39$ & 0.054 & .947 \\
& relaxation time (ms) & $54.47 \pm 9.31$ & $53.99 \pm 9.47$ & 0.021 & .979 \\
& maximum distance (mm) & $4.09 \pm 0.32$ & $3.71 \pm 0.35$ & .635 & .638 \\
& delayed time (ms) & $19.73 \pm 0.42$ & $19.22 \pm 0.32$ & 0.636 & .536 \\
\hline
\end{tabular}

